\title{
Damage Tolerance Assessment of a Brake Unit Bracket for High-Speed Railway Welded Bogie Frames
}

\author{
Bing Yang ${ }^{1^{*}} \mathbb{D}$, Hao Duan ${ }^{1}$, Shengchuan $\mathrm{Wu}^{1,2}$ and Guozheng Kang ${ }^{1}$
}

\begin{abstract}
The brake unit bracket of a bogie frame is an important load-carrying component, particularly under emergency start/stop conditions. Conventional infinite/safe life approaches provide an over-conservative recommendation for the allowable strength and lifetime, which hinders the lightweight design of modern railway vehicles. In this study, to ensure the reliability and durability of a brake unit bracket, an attempt was made to integrate the nominal stress method and an advanced damage tolerance method. First, a complex bogie frame was modelled using solid elements instead of plate and beam elements. A hot spot stress region on the bracket was found under an eight-stage load spectrum obtained from the Wuhan-Guangzhou high-speed railway line. Based on the probability of foreign damage, a semi-elliptical surface crack was then assumed for residual life assessment. The results obtained by the cumulative damage and damage tolerance methods show that the brake unit bracket can operate for over 30 years. Moreover, even if a 2-mm depth crack exists, the brake unit bracket can be safely operated for more than 2.27 years, with the hope that the crack can be detected in subsequent maintenance procedures. Finally, an appropriate safety margin was suggested which provides a basis for the life prediction and durability assessment of brake unit brackets of high-speed railways.
\end{abstract}

Keywords: Welded bogie frame, Fatigue damage accumulation, Damage tolerance design, Residual life assessment, High-speed railway vehicle

\section{Introduction}

The total distance covered by the Chinese high-speed railway network was approximately $29000 \mathrm{~km}$ at the end of 2018, and it is expected to reach $38000 \mathrm{~km}$ by 2025 . Safety and durability have become paramount. Among the safety-critical structures, the high-speed welded bogie frame is known to play a crucial role in transferring the static load acting on the vehicle to the hollow axles, in addition to controlling the wheelsets on straight and curved tracks and supporting the wheels, axles, brakes, and suspensions [1-3]. In general, the welded bogie frame is designed to operate for over 25 years with regular inspection according to the maintenance procedures.

\footnotetext{
*Correspondence: yb@swjtu.edu.cn

${ }^{1}$ State Key Laboratory of Traction Power, Southwest Jiaotong University, Chengdu 610031, China

Full list of author information is available at the end of the article
}

The welding process may not only lead to a strength/ geometry mismatch, but may also induce various defects such as inclusions, pores, cracks, and undercuts, thereby resulting in serious stress concentration under fatigue load [4-6]. Nevertheless, it is widely reported that some failures usually originate from extrinsic defects probably due to abnormal impact and vibration, and not from welded joints [7-9]. To tackle such problems, ample research has been conducted on materials and structures by performing elaborate simulations and experiments using standard procedures $[2,10,11]$. The locations with high stresses on a railway bogie can be accurately determined within the framework of the nominal stress approach by incorporating multibody system dynamics (MBSD) and/or finite element method (FEM) $[8,12,13]$.

To keep higher safety and reliability of bogie frames for a light rail vehicle, three fatigue assessment procedures in terms of equivalent stress ranges have been carefully 
examined using highly loaded welded joints, such as the endurance limit approach with the maximum loading amplitude, cumulative damage approach with the loading spectrum of fatigue test program, and cumulative damage approach with the vertical force range spectrum from MBS simulation. It has been confirmed that the MBS-based loading spectrum provides more realistic loads, which act on the bogie frame, for fatigue assessment, depending on the actual railway conditions [3, 14-16]. However, it is well-known that the fatigue assessment based on the endurance limit approach provides relatively conservative results for the allowable stress and accumulation damage; nevertheless, such an approach serves as a quick and standard procedure for the safe life analysis of railway safety-critical components [17-19]. Moreover, most studies have employed the simplified bogie frame model composed of hybrid solid and plate elements for the residual life prediction in the presence of defects [4, 20,21]. Novel assessment methods using the master $S-N$ curve, hot spot stress, and notch stress have been proposed to consider the uneven stress distribution due to geometry discontinuity or strain gradient $[14,22-$ 24]. Recently, a fracture mechanics-based damage tolerance design approach has been successfully applied to aircraft structures, high-speed railway axles, disc brakes, and nuclear pressure pipes for remaining life and resulting inspection interval predictions [25-29].

The brake unit of a bogie system is one of the vital structures significantly affecting the operation safety and ride comfort of high-speed railway vehicles. Furthermore, frequent deceleration and acceleration occur during operation because of routine stopping and starting. This might induce a high stress zone around the brake unit bracket, particularly while braking in an emergency.

This study conducts life prediction and durability assessment for the brake unit bracket of a bogie frame using a damage cumulative approach and an advanced damage tolerance design method. The mechanical properties, probabilistic fatigue $S-N$ curves, and fatigue crack growth (FCG) rate of a weathering steel were measured as important input parameters for the solid finite element model of the bogie frame. The standard NASGRO equation was selected as the fitted FCG rate model with stress ratios of -1 and 0 . To obtain the actual fatigue performance and lifetime, an eight-stage loading spectrum acting on the Wuhan-Guangzhou line was employed.

\section{Experimental Procedures}

\subsection{Materials}

The widely used weathering steel material consisting of equiaxial ferrite and pearlite was used for the bogie frame model under normalised and rolled states [30].
The mechanical properties obtained from the monotonic tensile tests with three effective specimens are listed as follows: $409 \mathrm{MPa}$ for the $0.2 \%$ offset proof yield strength $R_{\mathrm{p} 0.2}, 567 \mathrm{MPa}$ for the ultimate tensile strength $R_{\mathrm{m}}, 26 \%$ for the fracture elongation, 0.3 for the Poisson's ratio $v$, and $206 \mathrm{GPa}$ for the Young's modulus $E$. The main chemical compositions of the parent metal (PM) in terms of the maximum percentage weight include $0.19 \% \mathrm{C}, 0.035 \% \mathrm{~S}$ and $\mathrm{P}, 0.55 \% \mathrm{Si}, 0.70 \% \mathrm{Ni}, 0.35 \% \mathrm{Mo}$, and $0.17 \% \mathrm{Zr}$. The compositions of other alloying elements, such as $\mathrm{Mn}, \mathrm{Cr}$, and $\mathrm{Cu}$, vary in the ranges of $0.45 \%-1.60 \%, 0.35 \%-0.85 \%$, and $0.20 \%-0.60 \%$, respectively. The chemical compositions and basic properties of such a material with good toughness are comparable to those of hot-rolled SMA490BW.

Note that the semi-automated metal active gas (MAG) welding system was used to manufacture the bogie frames of China Railway high-speed $(\mathrm{CRH})$ railway vehicles, which have a speed range of $200-500 \mathrm{~km} / \mathrm{h}$. However, the present study focused on the failure effect of the PM plate (thickness of $10 \mathrm{~mm}$ ) with a high strain region, which was identified from a geometry-optimised bogie frame structure. The intrinsic strength/geometry mismatch due to the welding process has been effectively avoided by performing a detailed system dynamic simulation and a full-scale benchmark test. Therefore, the assessment was based on the fact that the crack was initiated far away from the welded zone.

\subsection{Experiments}

A standard monotonic tensile test was performed at a constant strain rate using an MTS 809 testing machine. This test served as a reference for the fatigue experiments. The strain rates were 0.005 and $2 \mathrm{~mm} / \mathrm{min}$ before and after the yield point, respectively.

Identical hourglass-shaped plate specimens as shown in Figure 1 (gauge size of $70 \times 10 \mathrm{~mm}^{2}$ ) were prepared for both low cycle fatigue (LCF, $R=-1$ and strain rate of $0.002 / \mathrm{s}$ ) and high cycle fatigue (HCF, $R=-1$ and alternating sinusoidal mode) tests. An MTS 810 servohydraulic testing machine and an INSTRON 8872 highfrequency fatigue machine were selected for the LCF and HCF tests, respectively. During the HCF testing, the tests were manually terminated when the lifetime exceeded $10^{7}$ cycles, thus indicating an unbroken specimen.

Based on the probabilistic endurance curves, the HCF results were used to conduct a safe life assessment test on the braking bracket using a conventional nominal stress method. However, to ensure the safety and reliability of the bracket in service, the cyclic stress-strain responses of the high strain region with a potential defect were measured to predict the FCG resistance. Under a 

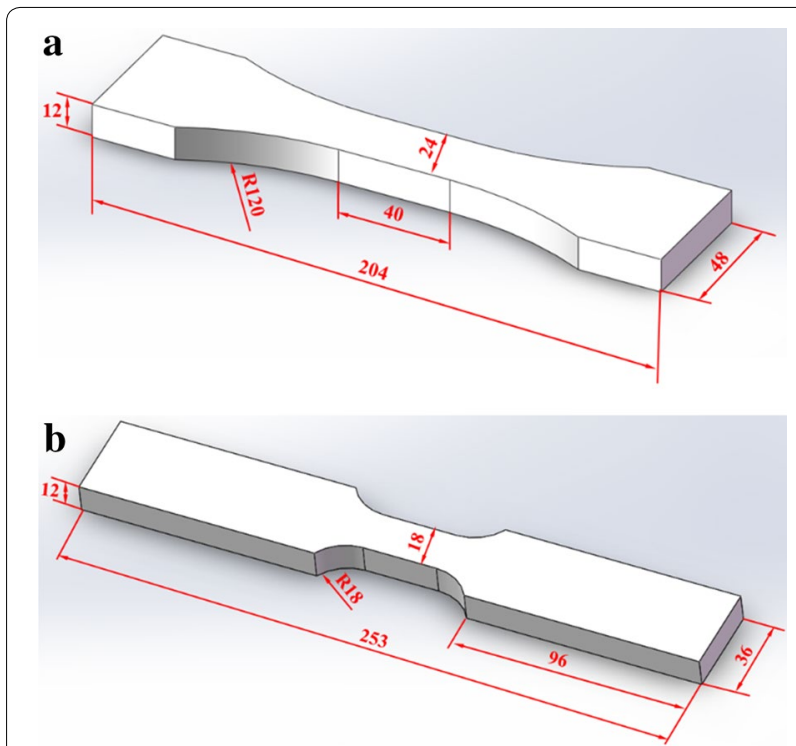

Figure 1 Geometry and dimensions in millimeters of specimens for: a LCF tests; $\mathbf{b}$ HCF tests

remote reversed loading, there exists a reversed plastic zone around the crack where the fatigue damage occurs. This shows that the LCF behaviour controls the fatigue cracking.

It has been widely argued that different geometries of the middle-crack tension (MT) and compact tension (CT) specimens can lead to considerable discrepancy in the FCG rate, even though the same ASTM E 647 standard is used under the same material and loading conditions [31, 32]. Therefore, for a reliable remaining life prediction based on the damage tolerance approach, the experimental long crack FCG rate and threshold stress intensity factor (SIF) range $\left(\Delta K_{\mathrm{th}}\right)$ were determined using standard MT specimens for $R=-1$ and 0 .

\section{Modelling}

\subsection{Constraint and Loading Conditions}

Figure 2 shows the structure of the modelled bogie frame, along with the applied braking forces and the corresponding constraint conditions. The bogie frame selected in this study is a box-type welded frame, consisting of two side beams and two cross beams, which form an $\mathrm{H}$-shaped frame.

To ensure the computational accuracy of the finite element analysis, most parts of the bogie frame were meshed using the structural eight-node solid brick element (linear C3D8 type in ABAQUS). Nevertheless, a few tetrahedron (C3D4 type) and pentahedron (C3D6 type) elements were used in the smooth transition parts

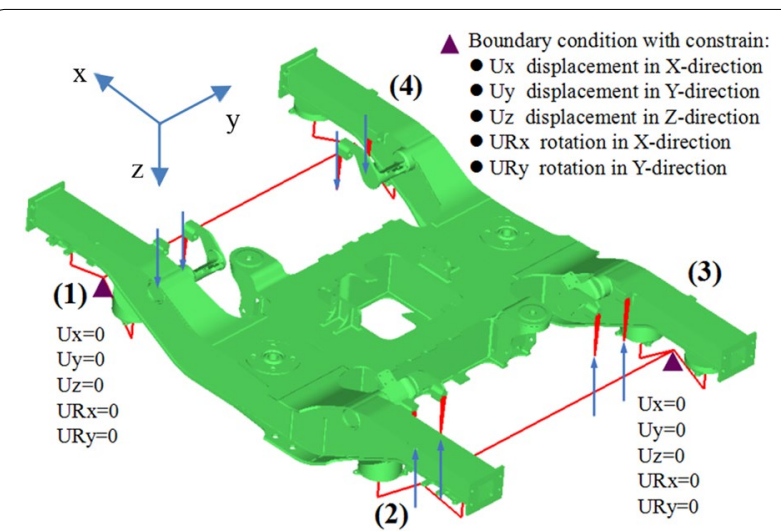

Figure 2 Bogie frame structure with braking forces and boundary conditions

for welding lines and the arc transition parts within the bogie frame, respectively. The element size was approximately $5 \mathrm{~mm}$, which corresponded to a total of 2557391 elements and 1938972 nodes for the bogie frame model. The weathering steel, which is used for the current bogie frame, was modelled as a linearly elastic material.

As shown in Figure 2, the locations (1) to (4) represent the axle boxes subjected to displacement constraints in the $x, y$, and $z$ directions and rotation ones about the $x$ and $y$ directions. To avoid any over-constraint or underconstraint, a virtual axle model is employed, as shown in Figure 3 . The primary suspension between the frame and the axle box is in the form of steel and rubber springs, represented by red lines, respectively. The stiffness values in the three directions are applied to the steel and rubber springs. The red lines represent the rigid beam elements, which are used to simulate the axle and axle box.

The braking forces, shown in Figure 2, are located at the mass centre points of the brake units, which are installed on the brake unit brackets. The braking forces acting on the brake unit brackets at the two ends of the bogie frame

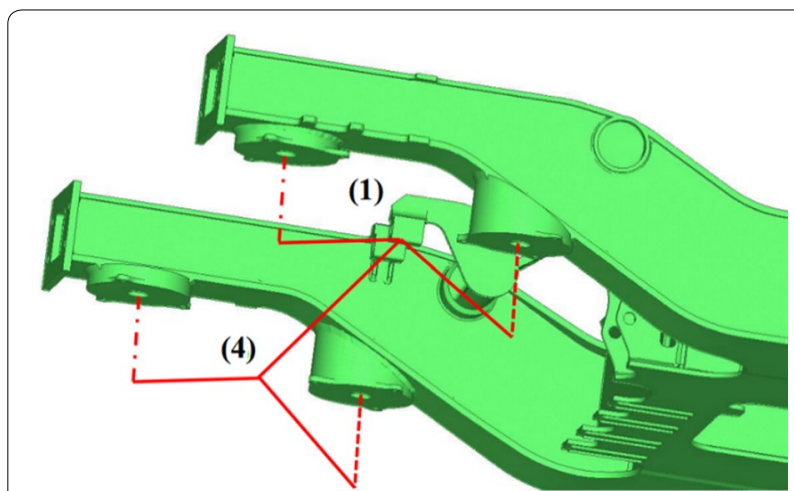

Figure 3 Virtual axle model simulating the primary suspension, rubber spring, axle, axle box, and the connecting relationship between them 
are equal in magnitude but opposite in direction. The eight-stage loading spectrum data (see Figure 4) obtained from the loading tests [33] on the Wuhan-Guangzhou line are used for the brake disc assessment. The load spectrum represents a distance of $76700 \mathrm{~km}$ of the CRH electrical multi-unit (EMU) at a speed of $350 \mathrm{~km} / \mathrm{h}$. The block loads $2-8$ occupy a small proportion of the spectrum, i.e., $4.3 \%$, whereas the block load 1 , which takes over $95 \%$ of the spectrum, corresponds to a very low load of approximately $3.32 \mathrm{kN}$.

The first principal stress distribution in the S11 direction of the bogie frame under peak load 1 is plotted to represent the loading capacity, as shown in Figure 5.

The maximum stress occurs clearly in the arc region of the brake unit bracket, where a relatively high stress concentration is observed under braking load. It is reasonable to assume that the crack initiates from the arc region.

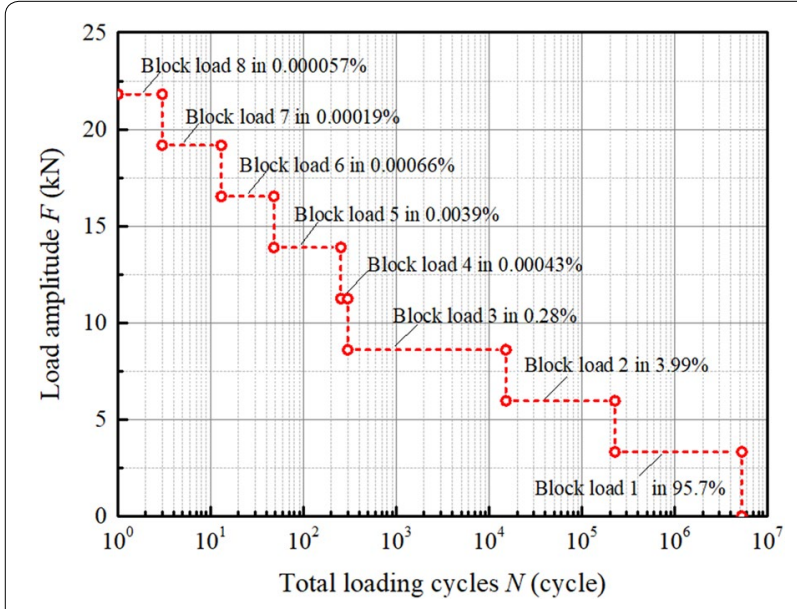

Figure 4 Eight-stage braking load spectrum obtained from the Wuhan-Guangzhou line of the CRH EMU

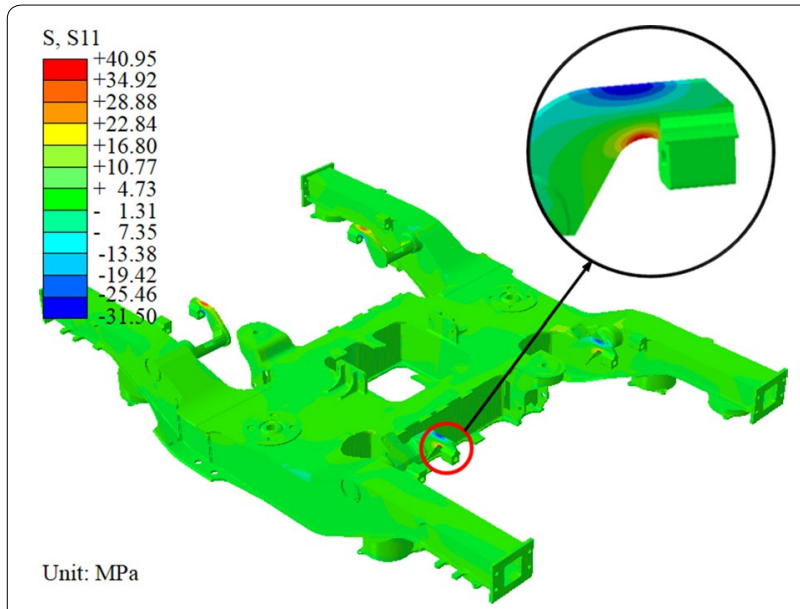

Figure 5 Stress distribution on the bogie frame under load 1
Hence, to ensure the accurate assessment to the safety and durability of the bracket, the meshes are refined locally with different crack depths so that a more accurate analysis of the FCG behaviour can be performed.

\subsection{Brake Unit Bracket with a Defect}

Ample theoretical and experimental studies have shown that a fatigue crack generally takes an elliptical or a semielliptical shape as observed from the fracture face. In the BS 7910 code, the single planar surface and embedded cracks or defects are generally characterised as standard elliptical or semi-elliptical shapes, and the maximum distances along the length and width directions are selected as the long and short axes, respectively. As shown in Figure 6, a semi-elliptical crack with an aspect ratio $(a / c)$ of 0.6 is introduced in the arc part where the maximum stress occurs. The minimum elemental edge along the crack front is one tenth of the crack depth $a$.
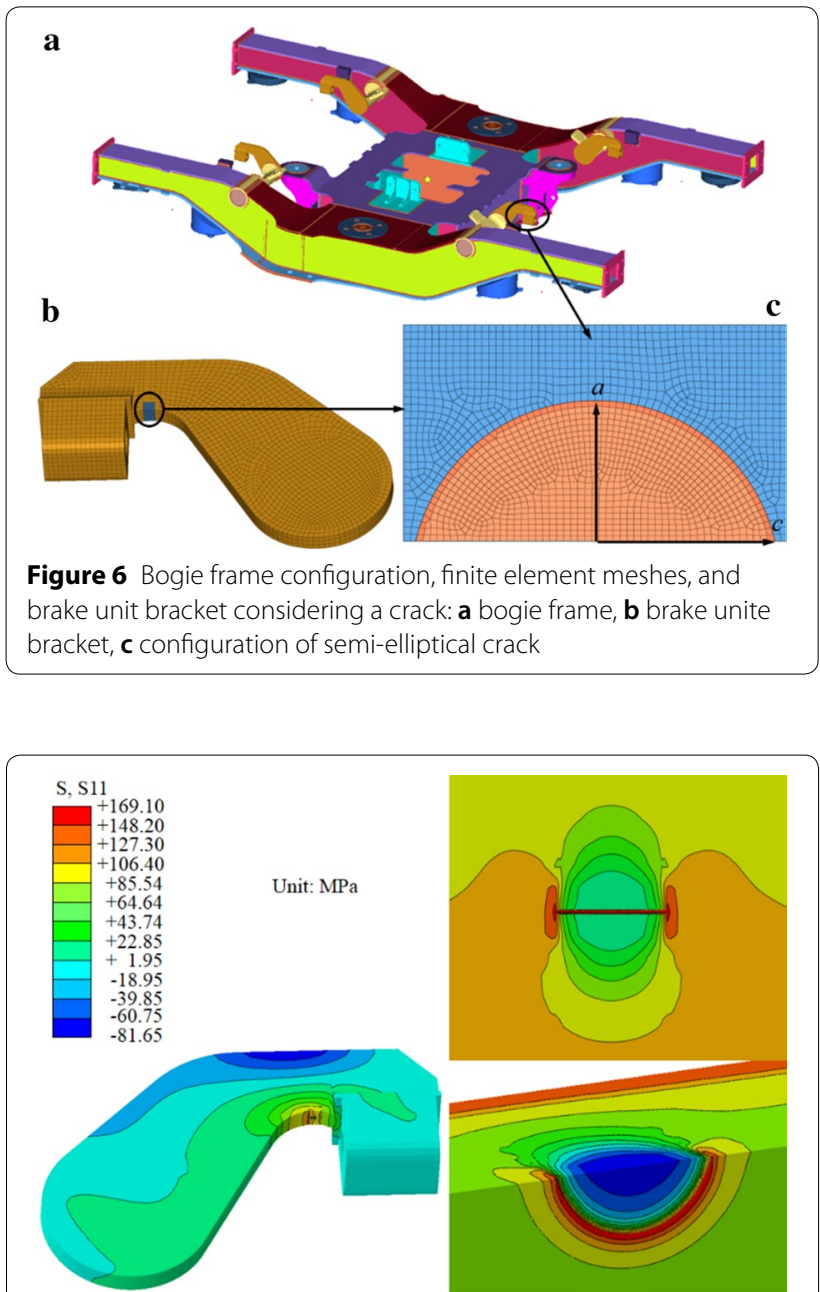

Figure 7 Result of brake unit bracket with a $1 \mathrm{~mm}$ crack under braking load 3 


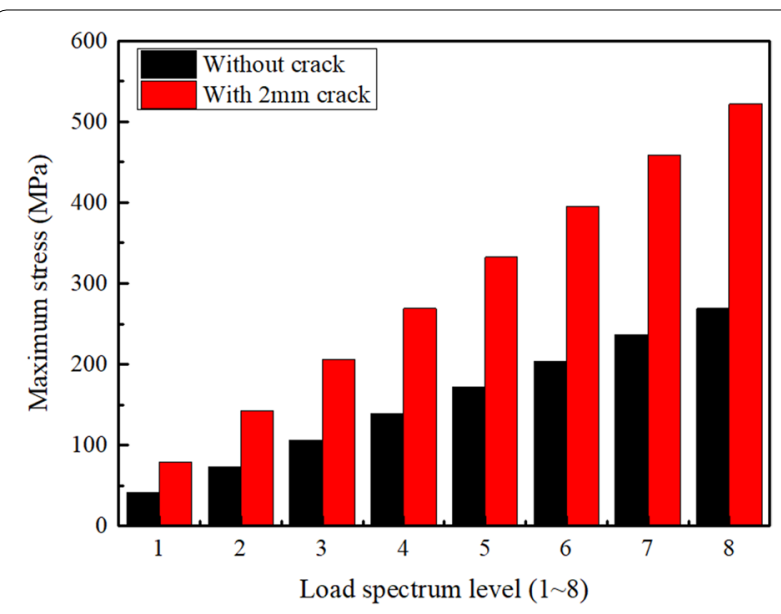

Figure 8 Maximum stress of brake unit bracket under eight-stage braking load spectrum

Figure 7 shows the principal stress distribution in the S11 direction with a $1 \mathrm{~mm}$ crack under load 3 (shown in Figure 4). A clear stress concentration is observed at the crack front, with a maximum stress of approximately 169.1 MPa. Once a crack is initiated in the stress concentration region, the stress at the crack front tends to be significantly higher than that in the case without a crack or any other defects. As a result, the calculated SIF range at the crack front increases rapidly. In this case, all the load levels, shown in Figure 4, contribute to the subsequent crack growth. This analysis shows that after introducing a crack in the model, the local stress state visibly deteriorates under the same external load condition. However, the local stress state under this condition is more realistic and accurate.

To further reflect the influence of a defect, a crack with a 2-mm depth was induced in the maximum stress region (see Figures 5 and 7) of the brake unit bracket. The eightstage braking load spectrum was applied to the bogie to evaluate the stress status. Figure 8 shows the first principal stress values for the structure with and without a defect.

It is clear that a defect can significantly amplify the stress in the arc region. This indicates that a crack may deteriorate the stress distribution of the bracket dramatically and lead to a sudden fatigue accident. Such a stress amplification phenomenon (see Figure 8) shows that the conventional nominal stress method is clearly unsuitable to evaluate damaged structures.

\subsection{Fatigue Damage}

\subsubsection{Low Cycle Fatigue}

It is generally believed that a cyclic plastic zone is locally consolidated before the crack penetrates the characteristic length [31, 32]. Such a global deformation phenomenon can be related with the local damage behaviour ahead of a growing crack, thus derives a crack growth model even under an elastic loading condition.

Figure 9 shows a mixed softening-hardening behaviour, which is in contrast to the monotonic tensile curve. The softening behaviour gradually changes to a hardening one with the increase in the cyclic strain amplitude. The cyclic yield stress $\left(\sigma_{\text {cy }}\right)$ is the stress at $0.2 \%$ strain on the cyclic stress-strain curve. This value can be determined by drawing a line parallel to the modulus of elasticity through the $0.2 \%$ strain offset at the zero stress point. The stress at which the line intersects the cyclic stress-strain curve is taken as the cyclic yield stress and is used in Eq. (1).

The cyclic stress-strain relationship, in Figure 9, shows a deformation behaviour, particularly when a crack is initiated. This study ignores the cyclic hardening
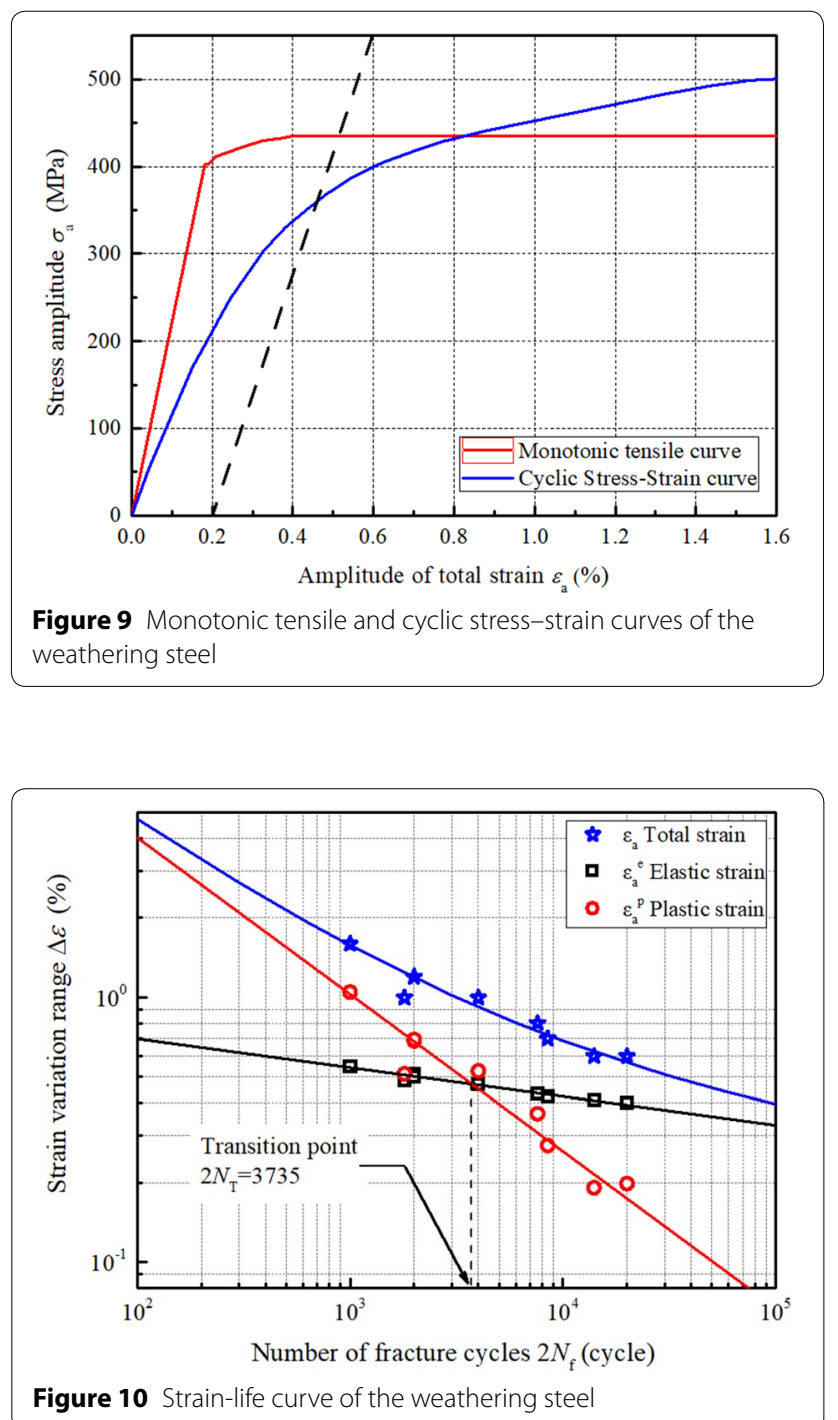
phenomenon while establishing the FCG rate model. Figure 10 shows the strain-life curve of the weathering steel including the elastic, plastic, and total strains. The elastic $\varepsilon_{\mathrm{a}}^{\mathrm{e}}$ and plastic strain amplitudes $\varepsilon_{\mathrm{a}}^{\mathrm{p}}$ were separated from the total one $\varepsilon_{\mathrm{a}}$. According to the Coffin-Manson relation and Basquin equation, the LCF life can be calculated using the following equation:

$$
\varepsilon_{a}=\varepsilon_{a}^{e}+\varepsilon_{a}^{p}=\frac{\sigma_{f}^{\prime}}{E}\left(2 N_{f}\right)^{b}+\varepsilon_{f}^{\prime}\left(2 N_{f}\right)^{c},
$$

where $E, \sigma_{f}^{\prime}, b, \varepsilon_{f}^{\prime}$, and $c$ are the Young's modulus, fatigue strength coefficient, fatigue strength index, fatigue toughness coefficient, and fatigue toughness index, respectively. The fatigue ductility properties of the weathering steel are $b=-0.109, c=-0.593, \sigma_{\mathrm{f}}^{\prime}=1298.57 \mathrm{MPa}$, and $\varepsilon_{\mathrm{f}}^{\prime}=0.310$.

For the present weathering steel, the transition life $\left(N_{\mathrm{T}}\right)$, which is the number of cycles when the elastic strain range is equal to the plastic one, is found to be 3735 cycles, as demonstrated in Figure 10. For a fatigue life less than $N_{\mathrm{T}}$, the plastic component prevails over the elastic one, whereas for a higher cycle number, the contrary is the case.

\subsubsection{High Cycle Fatigue}

As shown in Figure 11, the probabilistic fatigue $S-N$ curves and fatigue limits are concluded from the HCF experimental data. The fatigue strength limit is approximately $225 \mathrm{MPa}$ (at the knee point when $N_{\mathrm{D}}=3.62 \times 10^{6}$ cycles) with a survival probability of $50 \%$. The material parameters $C$ and $m$ in Eq. (2) for the $S-N$ curve are the basic data required for the fatigue life prediction using the cumulative damage approach.

$$
C=N_{i} \sigma_{\mathrm{a} i}^{m} \text {. }
$$

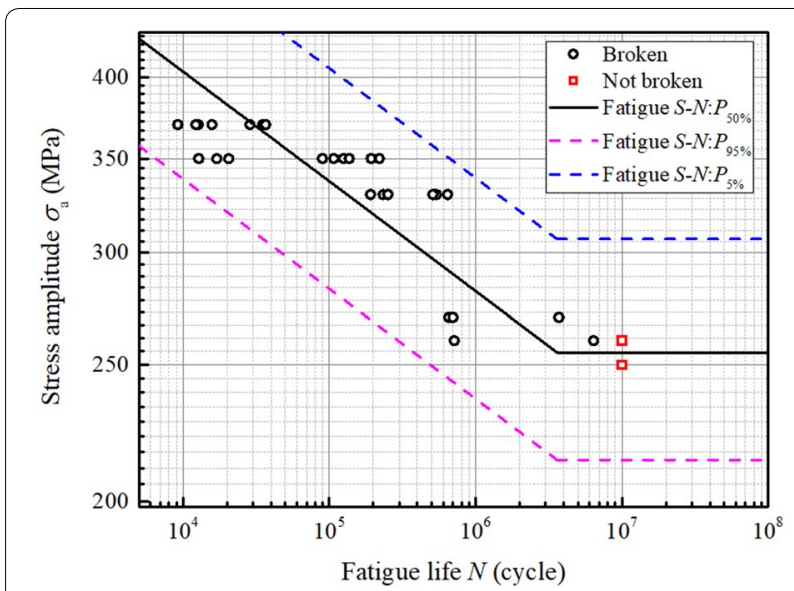

Figure 11 Fatigue S-N curves with survival probabilities of 5\%, 50\%, and $95 \%$ for weathering steel
The probabilistic fatigue $S-N$ curve with a survival probability of $95 \%$ and a confidence level of $95 \%$ is selected for the component design. This curve ensures the fatigue life at a specified stress level with the aforementioned reliability [34].

\section{Results and Discussions}

\subsection{Fatigue Limit Diagram Analysis}

The conventional and most frequently used method for the fatigue assessment of bogie frames is the fatigue limit diagram analysis along with the nominal stresses. It is a convenient and relatively conservative approach to quickly evaluate the fatigue design of frame structures. Table 1 lists the maximum and minimum principal stresses at several

Table 1 Analyzed stresses for the load spectrum shown

\begin{tabular}{|c|c|c|c|c|c|}
\hline $\begin{array}{l}\text { Load } \\
\text { spectrum }\end{array}$ & Position & $\sigma_{\max }(\mathrm{MPa})$ & $\sigma_{\min }(\mathrm{MPa})$ & $\sigma_{m}(\mathrm{MPa})$ & $\sigma_{\mathrm{a}}(\mathrm{MPa})$ \\
\hline \multirow[t]{4}{*}{1} & 1 & 35.09 & -34.90 & 0.10 & 34.99 \\
\hline & 2 & 39.47 & -36.80 & 1.34 & 38.14 \\
\hline & 3 & 29.23 & -27.43 & 0.90 & 28.33 \\
\hline & 4 & 30.30 & -31.46 & -0.58 & 30.88 \\
\hline \multirow[t]{4}{*}{2} & 1 & 66.08 & -69.61 & -1.76 & 67.85 \\
\hline & 2 & 73.29 & -70.86 & 1.22 & 72.07 \\
\hline & 3 & 56.48 & -56.10 & 0.19 & 56.29 \\
\hline & 4 & 54.78 & -49.81 & 2.49 & 52.30 \\
\hline \multirow[t]{4}{*}{3} & 1 & 100.45 & -104.53 & -2.04 & 102.49 \\
\hline & 2 & 95.36 & -102.34 & -3.49 & 98.85 \\
\hline & 3 & 71.76 & -79.05 & -3.65 & 75.40 \\
\hline & 4 & 81.95 & -81.50 & 0.23 & 81.72 \\
\hline \multirow[t]{4}{*}{4} & 1 & 133.63 & -124.63 & 4.50 & 129.13 \\
\hline & 2 & 138.63 & -136.21 & 1.21 & 137.42 \\
\hline & 3 & 103.80 & -98.97 & 2.41 & 101.38 \\
\hline & 4 & 105.32 & -106.51 & -0.60 & 105.92 \\
\hline \multirow[t]{4}{*}{5} & 1 & 154.01 & -145.13 & 4.44 & 149.57 \\
\hline & 2 & 150.08 & -148.85 & 0.62 & 149.47 \\
\hline & 3 & 114.73 & -122.30 & -3.78 & 118.52 \\
\hline & 4 & 131.63 & -127.68 & 1.97 & 129.65 \\
\hline \multirow[t]{4}{*}{6} & 1 & 183.29 & -196.52 & -6.62 & 189.90 \\
\hline & 2 & 203.27 & -200.94 & 1.16 & 202.10 \\
\hline & 3 & 160.54 & -151.95 & 4.30 & 156.24 \\
\hline & 4 & 155.59 & -156.64 & -0.53 & 156.12 \\
\hline \multirow[t]{4}{*}{7} & 1 & 227.90 & -223.50 & 2.20 & 225.70 \\
\hline & 2 & 233.03 & -233.03 & 0.00 & 233.03 \\
\hline & 3 & 168.79 & -176.21 & -3.71 & 172.50 \\
\hline & 4 & 180.44 & -181.66 & -0.61 & 181.05 \\
\hline \multirow[t]{4}{*}{8} & 1 & 241.83 & -259.29 & -8.73 & 250.56 \\
\hline & 2 & 268.19 & -265.13 & 1.53 & 266.66 \\
\hline & 3 & 192.03 & -200.48 & -4.22 & 196.25 \\
\hline & 4 & 205.29 & -206.68 & -0.69 & 205.98 \\
\hline
\end{tabular}
in Figure 4 
points on the brake unit bracket after the FE calculations under the eight-stage braking load spectrum. According to the tensile test results, given in Section 2.1 and Figure 9, the $0.2 \%$ offset proof yield strength $R_{\mathrm{p} 0.2}$ and the ultimate tensile strength $R_{\mathrm{m}}$ are $409 \mathrm{MPa}$ and $567 \mathrm{MPa}$, respectively. The FKM Guideline [35] has suggested a safety factor of 1.35 corresponding to the yield strength of steel structures. As a result, the permissible stress at the yield point of the weathering steel is approximately $303 \mathrm{MPa}$.

Moreover, the allowable fatigue stress is $155 \mathrm{MPa}$. The mean stress $\sigma_{\mathrm{m}}=\left(\sigma_{\max }+\sigma_{\min }\right) / 2$ and stress amplitude $\sigma_{\mathrm{a}}=\left(\sigma_{\max }-\sigma_{\min }\right) / 2$ were then calculated. The values are indicated in the Goodman diagram shown in Figure 12. The data points under the load levels 1-5 are below the PM line, whereas the data points under the load levels 6-8 are above the line. Therefore, although only a small proportion of the load spectrum is occupied by the load levels $6-8$ (i.e., only approximately $0.000907 \%$ ), the fatigue strength of the brake unit bracket could not meet the requirements of the fatigue design. However, as discussed above, although the fatigue limit diagram analysis is convenient, it can be over-conservative.

\subsection{Cumulative Damage Approach}

The structural design of a brake unit bracket using the fatigue limit diagram approach is rather conservative. To predict the fatigue life and determine the validity of the braking load conditions more accurately, the cumulative fatigue damage approach was applied. Based on the eightstage braking load spectrum, the cumulative damage $D$ was subsequently calculated using the linear damage accumulation Palmgren-Miner rule as shown in Eq. (3):

$$
D=\sum_{i=1}^{k} \frac{n_{i}}{N_{i}} .
$$

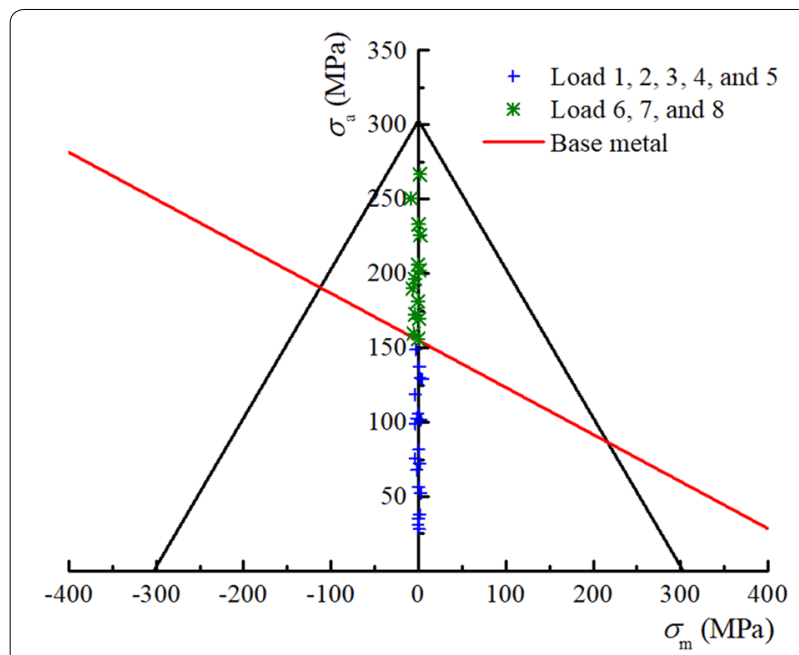

Figure 12 Goodman diagram for brake unit bracket under the eight-stage braking load spectrum
A significant proportion of the eight-stage load spectrum is occupied by cycles at relatively lower stress levels. Therefore, the contribution of these cycles to the fatigue damage must be considered. To reasonably consider the damage caused by all the stress levels, the actual cumulative damage $D_{\text {act }}$ of the eight-stage load spectrum was derived based on the Miner linear fatigue cumulative damage rule and the $S$ - $N$ curve obtained from the HCF tests.

$$
D_{\mathrm{act}}=\sum_{i=1}^{8} \frac{n_{i}}{N_{i}}=\sum_{i=1}^{8} \frac{n_{i} \sigma_{\mathrm{a} i}^{m}}{C} .
$$

After obtaining $D_{\text {act }}$ by Eq. (4) and corresponding distance $L_{\text {act }}$, which was introduced in another study [33], the total operation distance $L$ of the brake unit bracket can be calculated as follows:

$$
\frac{D_{\text {cri }}}{L_{\text {cri }}}=\frac{D_{\text {act }}}{L_{\text {act }}},
$$

where $D_{\text {cri }}$ is the total critical damage with a recommended value of 0.3 according to the FKM Guideline [35] for non-welded components of steel materials.

The calculated results show that $D_{\text {act }}=3.44 \times 10^{-6}$ and $L_{\text {cri }}=6.68 \times 10^{9} \mathrm{~km}$. If the operating mileage of the CRH is set to be $600000 \mathrm{~km}$ per year, the brake unit bracket of the bogie frame can be safely used for 11136.5 years, which is more than adequate. It is generally assumed that the total lifetime of railway bogie frames is approximately 25 years. Therefore, the brake unit bracket satisfies the service requirement.

However, if a crack with a depth of $2 \mathrm{~mm}$ (which is equal to the minimum detectable crack size using current detection techniques $[8,17,29,32,36])$ already exists in the arc part of the brake unit bracket, the damage value will increase to $D_{\text {act }}=1.69 \times 10^{-2}$, thus reducing the total distance to $L_{\text {cri }}=1.36 \times 10^{6} \mathrm{~km}$. In this case, the total service life of the brake unit bracket is 2.27 years, which still meets the safety requirement of the maintenance policy (grade 2) for the Chinese high-speed railway. Therefore, the safety of the brake unit bracket can be guaranteed before the critical crack is detected.

It is worth noting that the proportion of loads $5-8$ in the load spectrum is lower than $0.1 \%$; however, the damage due to these loads accounts for as much as $98.27 \%$ of the total damage. This interesting result shows that although the frequency of high loads is low, it significantly affects the damage accumulation.

\subsection{Damage Tolerant Approach}

The shortcoming of the conventional design is that it considers the material as a homogeneous continuum without defects. In fact, initial defects are almost 
inevitable in such structures, thereby in turn making the actual strength lower than the nominal value. In contrast, the fracture mechanics-based approach considers that the structure is defective, which forms the basis for investigating the fracture failure mechanism and carrying out the safety evaluation.

\subsubsection{Fatigue Crack Growth Rate}

Recent studies have shown that the fatigue life predictions using the Miner cumulative damage rule can be over conservative even under the upper level of the service load spectrum. This is partially attributed to the intrinsic geometry discontinuity and extrinsic defects. Hence, to achieve a verifiable residual life, the assessment should be based on the framework of damage tolerance for a long crack. Figure 13 shows the obtained experimental FCG data, including the analytical solutions from the upper, lower, and optimal NASGRO models as described below [37]. As the residual life assessment is closely related to the value
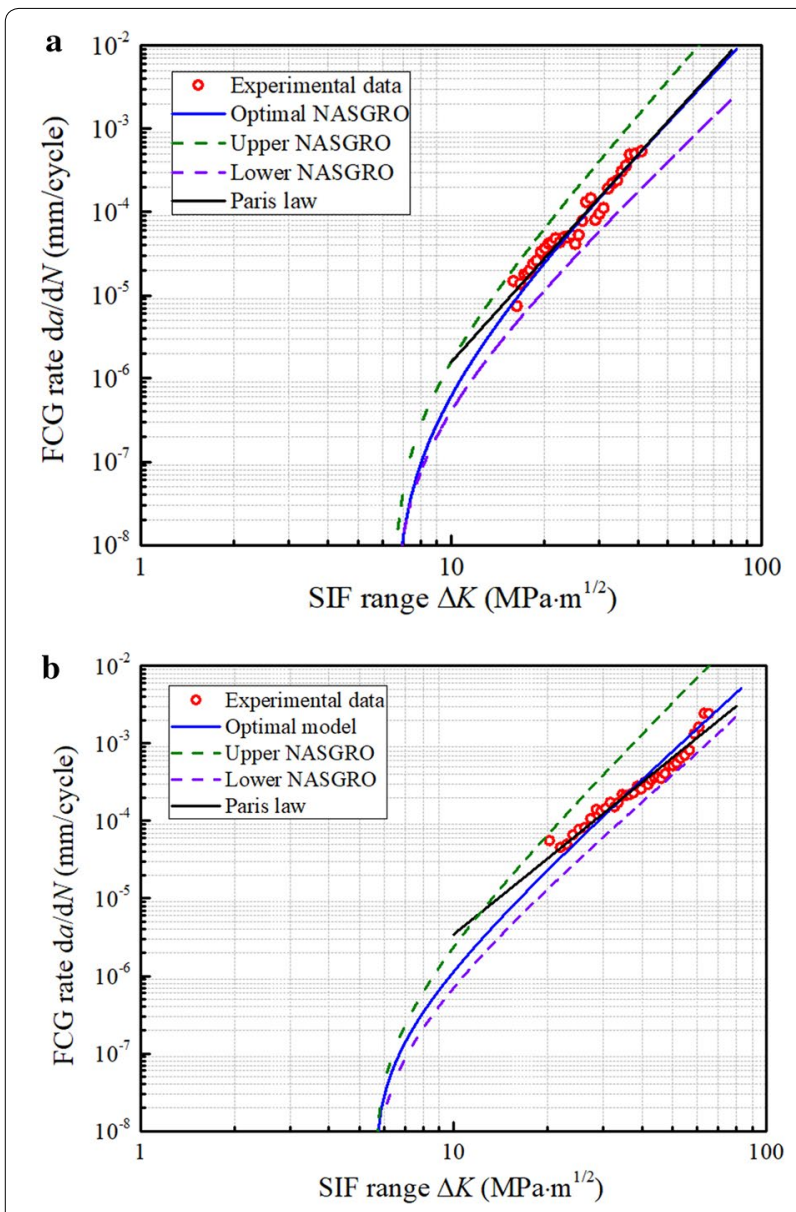

Figure 13 Comparison of predicted FCG curves via upper, lower, and optimal NASGRO models and classical Paris equation with experimental data of weathering steel for: $\mathbf{a} R=-1 ; \mathbf{b} R=0$ of threshold SIF range, it is important to determine this parameter properly. In present study, the threshold SIF range is experimentally obtained in accordance with the requirements described in ASTM E 647 standard using MT specimens. The threshold SIF ranges are 6.49 and 5.51 $\mathrm{MPa} \cdot \mathrm{m}^{-1 / 2}$ when $R=-1$ and 0 , respectively.

$$
\frac{\mathrm{d} a}{\mathrm{~d} N}=C \cdot \Delta K_{\mathrm{eff}}^{m}\left(1-\frac{\Delta K_{\mathrm{th}}}{\Delta K}\right)^{p}\left(1-\frac{K_{\mathrm{max}}}{K_{\mathrm{IC}}}\right)^{-q},
$$

where $\Delta K_{\mathrm{th}}, \Delta K_{\mathrm{eff}}$, and $\Delta K_{\max }$ are the threshold, effective, and maximum SIF ranges, respectively. $C$ and $m$ are the parameters in the Paris formula obtained from the FCG rate test, and $K_{\mathrm{IC}}$ is the fracture toughness. $p$ and $q$ are artificially fitted parameters from the experimental data.

To consider the plasticity-induced crack closure effect, a crack opening function $f$ can be introduced to modify $\Delta K$ and $\Delta K_{\text {th }}$ as follows $[8,17,29,32]$ :

$$
\begin{aligned}
& \Delta K_{\mathrm{eff}}=K_{\mathrm{max}}-K_{\mathrm{op}}=\frac{1-f}{1-R} \Delta K \\
& \Delta K_{\mathrm{th}, \mathrm{eff}}=\frac{1-f}{1-R} \Delta K_{\mathrm{th}} \\
& f= \begin{cases}\max \left(R, A_{0}+A_{1} R+A_{2} R^{2}+A_{3} R^{3}\right), & R \geq 0 \\
A_{0}+A_{1} R, & -2 \leq R<0\end{cases} \\
& A_{0}=\left(0.825-0.34 \alpha+0.05 \alpha^{2}\right) \cdot\left[\cos \left(\pi \sigma_{\max } / 2 \sigma_{\mathrm{cy}}\right)\right]^{1 / \alpha} \\
& A_{1}=(0.415-0.071 \alpha) \cdot\left(\sigma_{\mathrm{max}} / \sigma_{\mathrm{cy}}\right) \\
& A_{2}=1-A_{0}-A_{1}-A_{3}, \\
& A_{3}=2 A_{0}+A_{1}-1,
\end{aligned}
$$

where $K_{\max }, \sigma_{\max }, \sigma_{\mathrm{cy}}$, and $K_{\mathrm{op}}$ are the maximum SIF, maximum nominal stress, cyclic yield stress obtained from the LCF test, and SIF required to fully open a crack, respectively. $A_{0}, A_{1}, A_{2}$, and $A_{3}$ are the coefficients of the Newman function $f$. $\alpha$ is the constraint parameter related to the stress status; here $\alpha=3.0$. The predicted curves based on the NASGRO model can be used to accurately estimate the FCG rate, particularly when the SIF range is close to the threshold region.

\subsubsection{Residual Life Assessment}

The fatigue performance of the brake unit bracket has been investigated using the classical nominal stress method. Over conservative lifetime predictions were obtained for the fatigue strength limit and permissible damage accumulation. To further enhance the durability, the brake unit bracket with existing defects was comprehensively investigated in terms of the fracture mechanics. Figure 14 shows the SIF range as a function of the 


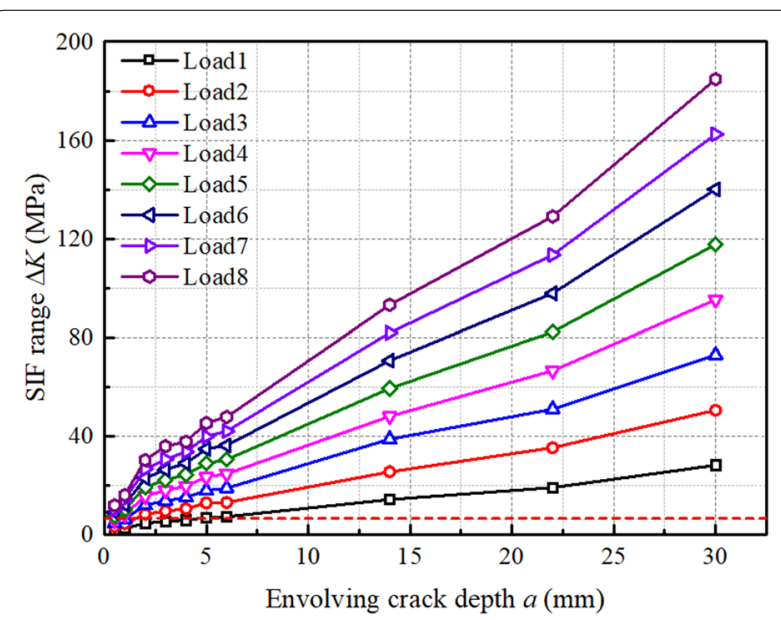

Figure 14 FCG driving force curves at the deepest point of a growing crack for the brake unit bracket under load spectrum

crack depth under different loading conditions, wherein an initial semi-elliptical crack with a depth of $0.5 \mathrm{~mm}$ is included in the arc part of the brake unit bracket. This provides a qualitative evaluation of the fatigue property of the brake unit bracket.

With the increase in the crack depth, the SIF range clearly increases. When the crack depth $(a)$ is $0.5 \mathrm{~mm}$ under the loads $1-4$, the calculated SIF range $\Delta K$ is lower than the threshold SIF range $\Delta K_{\text {th }}$ when $R=-1$. In contrast, under the loads 5-8, $\Delta K$ is greater than $\Delta K_{\text {th }}$.

Based on the experimental data, shown in Figure 13(a), Figure 15 shows the predicted FCG curves of the brake unit bracket subjected to actual fatigue load sequences considering a semi-elliptical crack with a $2.0 \mathrm{~mm}$ depth.

According to Figure 15, the lifetime of the brake unit bracket can be estimated from the initial crack depth of

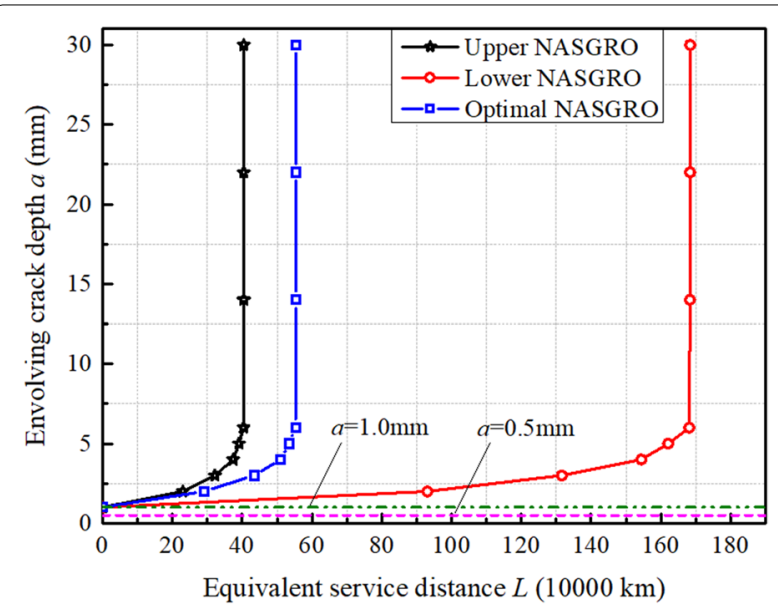

Figure 15 Predicted life of brake unit bracket with an initial crack of $2 \mathrm{~mm}$ depth
$2 \mathrm{~mm}$ to half the height of the brake unit bracket, i.e., $30 \mathrm{~mm}$. The lifetime values obtained using the upper, optimal, and lower NASGRO models are $4.05 \times 10^{5} \mathrm{~km}$, $5.54 \times 10^{5} \mathrm{~km}$, and $1.69 \times 10^{6} \mathrm{~km}$, respectively. It should be noted that the fatigue crack would propagate rapidly once $a>3.0 \mathrm{~mm}$, which corresponds to approximately $5.54 \times 10^{5} \mathrm{~km}$ as per the optimal NASGRO model. To analyse the influence of the initial crack depth, the fatigue lives of the brake unit bracket with crack depths of 0.5 and $1 \mathrm{~mm}$ were also calculated. The equivalent service distances are approximately $4.24 \times 10^{7} \mathrm{~km}$ and $3.01 \times 10^{6}$ $\mathrm{km}$, respectively, according to the optimal NASGRO model; these values are significantly greater than those when the initial crack depth is $2 \mathrm{~mm}$. The fatigue life of the brake unit bracket could satisfy the service requirement of the bogie for all the initial crack depths considered. The initial crack depth significantly influences the fatigue life of the brake unit bracket, i.e., the life calculated with a $0.5 \mathrm{~mm}$ initial crack is 145.7 times that calculated with a $2-\mathrm{mm}$ initial crack. Therefore, to obtain a more rational prediction of the fatigue life of the brake unit bracket, it is very important to detect the initial crack as carefully and accurately as possible.

However, it is worth noting that the results predicted using the three different NASGRO models were completely based on the artificially fitted parameters, and therefore, show a significant deviation. The equivalent service distance obtained using the lower NASGRO model is approximately four times that obtained using the upper NASGRO model. This is a disadvantage of the NASGRO model, which might consequently lead to significant error accumulation.

\section{Conclusions}

The fatigue life of a brake unit bracket under a measured braking load spectrum was predicted by integrating the standard nominal stress method and an advanced damage tolerance method. Prior to this, the static strength of a box-type welded frame, which is here modelled using high-accuracy solid elements rather than relatively simple plate and shell elements widely used, was first evaluated by adopting the finite element method. To perform the residual life assessment in the presence of a crack, the FCG rate was characterised using three different NASGRO models based on the data of FCG rate test. The following conclusions can be drawn from this study:

(1) According to the finite element calculation under braking loads, a semi-elliptical crack with different depths was introduced in the stress concentrated area of the model, i.e., in the arc region of the brake unit bracket. 
(2) Based on the classical Miner rule, the damage is argued to be $D=0.3$ to ensure a service life of over 30 years for the brake unit bracket under an eightstage braking load spectrum. Even if a crack with a 2-mm depth exists, the brake unit bracket can be safely operated for more than 2.27 years.

(3) The calculated residual fatigue life of the brake unit bracket with an initial crack having a $2-\mathrm{mm}$ depth was found to be approximately $5.54 \times 10^{5} \mathrm{~km}$ based on the optimal NASGRO model. This can fully ensure the service safety and reliability of the bracket so that the crack can be detected in the subsequent maintenance process.

In future study, it is reasonably expected to introduce the multibody system dynamics to improve current static analysis. This is to take the influence of random loading spectrum into consideration especially when small-radius curved track exists. Besides, some defects, such as the lack of penetration and the lack of fusion during the welding, should be modelled according to non-destructive inspection or engineering experiences.

\section{Authors' Contributions}

BY and SW wrote the manuscript and guided the numerical simulations; HD carried out the experimental analyses and the numerical simulations; SW and GK guided the experiments. All authors read and approved the final manuscript.

\section{Author Details \\ 1 State Key Laboratory of Traction Power, Southwest Jiaotong University, Chengdu 610031, China. ${ }^{2}$ State Key Laboratory for Strength and Vibration of Mechanical Structures, Xi'an Jiaotong University, Xi'an 710049, China.}

\section{Authors' Information}

Bing Yang, born in 1979, is currently an associate professor at State Key Laboratory of Traction Power, Southwest Jiaotong University, China. He received his PhD degree from Southwest Jiaotong University, China, in 2011. His research interests include strength of vehicle structure and fatigue and fracture of materials.

Hao Duan, born in 1993, is currently a master candidate at State Key Laboratory of Traction Power, Southwest Jiaotong University, China. His research interests include damage tolerance analysis of railway bogie welded framework.

Shengchuan Wu, born in 1979, is currently a professor at State Key Laboratory of Traction Power, Southwest Jiaotong University, China. He received his PhD degree from Huazhong University of Science and Technology, China, in 2009. His research interests include damage tolerance design of high-speed railway structures and fatigue damage evaluation of lightweight metallic materials via high-resolution synchrotron radiation microtomography.

Guozheng Kang, born in 1969, is currently a professor at State Key Laboratory of Traction Power and School of Mechanics and Engineering, Southwest Jiaotong University, China. He received his PhD degree from Southwest Jiaotong University, China, in 1997. His research interests include cyclic constitutive models, fatigue and fretting fatigue.

\section{Competing Interests}

The authors declare that they have no competing interests.

\section{Funding}

Supported by National Natural Science Foundation of China (Grant No. 11572267), Sichuan Science and Technology Program (Grant No. 2017JY0216), Open Research Project of State Key Laboratory for Strength and Vibration of Mechanical Structures of China (Grant No. SV2016-KF-21), and Open
Research Project of State Key Laboratory of Traction Power of China (Grant No. 2018TPL_T03).

Received: 26 November 2018 Revised: 3 June 2019 Accepted: 24 June 2019

Published online: 05 July 2019

\section{References}

[1] Y Gao, Q Liu, Y Wang, et al. Lightweight design with weld fatigue constraints for a three-axle bogie frame using sequential approximation optimisation method. International Journal of Vehicle Design, 2017, 73(1-3): 3-19.

[2] JW Seo, H M Hur, H K Jun, et al. Fatigue design evaluation of railway bogie with full-scale fatigue test. Advances in Materials Science and Engineering, 2017, 2017: 5656497.

[3] C Huang, J Zeng, G Luo, et al. Numerical and experimental studies on the car body flexible vibration reduction due to the effect of car bodymounted equipment. Proceedings of the Institution of Mechanical Engineers Part F- Journal of Rail and Rapid Transit, 2016, 232(1): 103-120.

[4] D Fu, W Wang, L Dong. Analysis on the fatigue cracks in the bogie frame. Engineering Failure Analysis, 2015, 58(1): 307-319.

[5] SCWu, Y N Hu, H Duan, et al. On the fatigue performance of laser hybrid welded high $\mathrm{Zn} 7000$ alloys for next generation railway components. International Journal of Fatigue, 2016, 91(1): 1-10.

[6] S J Kwon, J W Seo, J C Kim, et al. Defect evaluation for weld specimen of bogie using infrared thermography. Journal of the Korean Society for Precision Engineering, 2015, 32(7): 619-625.

[7] B H Park, KY Lee. Bogie frame design in consideration of fatigue strength and weight reduction. Proceedings of the Institution of Mechanical Engineers Part F- Journal of Rail and Rapid Transit, 2006, 220(3): 201-206.

[8] U Zerbst, R A Ainsworth, HT Beier, et al. Review on fracture and crack propagation in weldments - A fracture mechanics perspective. Engineering Fracture Mechanics, 2014, 132: 200-276

[9] B H Park, N P Kim, J S Kim, et al. Optimum design of tilting bogie frame in consideration of fatigue strength and weight. Vehicle System Dynamics, 2006, 44(12): 887-901.

[10] Z Ren, S Sun, Q Li, et al. Experimental studies of load characteristics of bogie frames for $350 \mathrm{~km} / \mathrm{h}$ EMUs. Proceedings of the Institution of Mechanical Engineers Part F- Journal of Rail and Rapid Transit, 2012, 226(2): 216-227.

[11] S Palli, R Koona. Analyses of dynamic response of a railway bogie. International Journal of Vehicle Noise and Vibration, 2015, 11(2): 103-113.

[12] J S Kim. Fatigue assessment of tilting bogie frame for Korean titling train: Analysis and static tests. Engineering Failure Analysis, 2006, 13(8): 1326-1337.

[13] S H Baek, S S Cho, W S Joo. Fatigue life prediction based on the rainflow cycle counting method for the end beam of a freight car bogie. International Journal of Automotive Technology, 2008, 9(1): 95-101.

[14] M Kassner. Fatigue strength analysis of a welded railway vehicle structure by different methods. International Journal of Fatigue, 2012, 34(1): 103-111.

[15] R Persson, E Andersson, S Stichel, et al. Bogies towards higher speed on existing tracks. International Journal of Rail Transportation, 2014, 2(1): 40-49.

[16] KJ Kim, J M Lee, N J Lee, et al. Prediction of dynamic loads on the aluminum bogie of a maglev vehicle using flexible multibody dynamics. Conference of the Korean Society for Railway, Seoul, Korea, May 11-13, 2009: 2773-2778.

[17] S CWu, Y X Liu, C H Li, et al. On the fatigue performance and residual life of intercity railway axles with inside axle boxes. Engineering Fracture Mechanics, 2018, 197: 176-191.

[18] M L Zhu, L Jin, F Z Xuan. Fatigue life and mechanistic modeling of interior micro-defect induced cracking in high cycle and very high cycle regimes. Acta Materialia, 2018, 157: 259-275.

[19] S P Zhu, S Foletti, S Beretta. Probabilistic framework for multiaxial LCF assessment under material variability. International Journal of Fatigue, 2017, 103: 371-385 
[20] J S Goo, J S Kim, K B Shin. Evaluation of structural integrity after ballastflying impact damage of a GFRP lightweight bogie frame for railway vehicles. Journal of Mechanical Science and Technology, 2015, 29(6): 2349-2356.

[21] Z Redouan, B Ahmed, L Mohammed. The mechanical fracture of a railway bogie under cyclic loading by Ansys. MATEC Web of Conferences, 2015, 28: 03002.

[22] P Dong, M Prager, D Osage. The design master S-N curve in ASME Div 2 rewrite and its validations. Weld in the World, 2007, 51(5-6): 53-63.

[23] A Esderts, J Willen, M Kassner. Fatigue strength analysis of welded joints in closed steel sections in rail vehicles. International Journal of Fatigue, 2012, 34(1): 112-121.

[24] M Leitner, M Stoschka, M Ottersböck. Fatigue assessment of welded and high frequency mechanical impact (HFMI) treated joints by master notch stress approach. International Journal of Fatique, 2017, 101(2): 232-243.

[25] R C Alderliesten, J J Homan. Fatigue and damage tolerance issues of glare in aircraft structures. International Journal of Fatigue, 2006, 28(10): 1116-1123.

[26] S C Wu, S Q Zhang, Z W Xu. Thermal crack growth-based fatique life prediction due to braking for a high-speed railway brake disc. International Journal of Fatigue, 2016, 87: 359-369.

[27] N O Larrosa, R Akid, R A Ainsworth. Corrosion-fatigue: a review of damage tolerance models. International Materials Reviews, 2017, 63(5): 283-308.

[28] S Ye, C C Zhang, PY Zhang, et al. Fatigue life prediction of nickel-based GH4169 alloy on the basis of a multi-scale crack propagation approach. Engineering Fracture Mechanics, 2018, 199: 29-40.
[29] S C Wu, ZW Xu, Y X Liu, et al. On the residual life assessment of highspeed railway axles due to induction hardening. International Journal of Rail Transportation, 2018, 6(4): 218-232.

[30] Y Liu, H Chen, Y Liu, et al. Simulated HAZ continuous cooling transformation diagram of a bogie steel of high-speed railway. International Journal of Modern Physics B, 2017, 31: 1744038

[31] I Varfolomeev, M Luke, M Burdack. Effect of specimen geometry on fatigue crack growth rates for the railway axle material EA4T. Engineering Fracture Mechanics, 2011, 78(5): 742-753.

[32] S C Wu, ZW Xu, C Yu, et al. A physically short fatigue crack growth approach based on low cycle fatigue properties. International Journal of Fatigue, 2017, 103: 185-195.

[33] X L Shi. Research on the fatigue life evaluation of forging brake disc used for high speed trains. Beijing Jiaotong University, Doctoral dissertation, 2016. (in Chinese).

[34] Y L Lee, J Pan, R B Hathaway, et al. Fatigue testing and analysis: Theory and practice. Burlington: Elsevier Butterworth-Heinemann, 2005.

[35] FKM-Guideline. Analytical strength assessment of components in mechanical engineering. Frankfurt a.M: Forschungskuratorium Maschinenbau (FKM), 2003

[36] L Náhlík, P Pokorný, M Ševčík, et al. Fatigue lifetime estimation of railway axles. Engineering Failure Analysis, 2017, 73: 139-157.

[37] J Maierhofer, R Pippan, H P Gänser. Modified NASGRO equation for physically short cracks. International Journal of Fatigue, 2014, 59: 200-207.

\section{Submit your manuscript to a SpringerOpen ${ }^{\circ}$ journal and benefit from:}

- Convenient online submission

- Rigorous peer review

- Open access: articles freely available online

- High visibility within the field

- Retaining the copyright to your article

Submit your next manuscript at $\boldsymbol{\nabla}$ springeropen.com 